\title{
Flipped Classroom and Its Impacts on College Courses Teaching
}

\author{
Lizhi Kong and Suolan Liu * \\ Changzhou University, Jiangsu, China, 213164 \\ lan-liu@163.com
}

Keywords: Flipped Classroom; Students; Teachers; Impact; Challenges

\begin{abstract}
The traditional teaching mode is mainly based on teaching knowledge in the form of class-based system. Flipped classroom is a transformation of traditional classroom teaching. Such teaching organizational forms with the traditional system of class instruction and academic system have different ideas and methods. As a new teaching mode, breaking the traditional limitation of giving lessons system, it has many differences in the teaching management such as objective, courses, resources, evaluation. But it encounters many problems in the basic teaching practice. Properly understand the meaning of flipped classroom and grasp its essential attributes has great help in the reform of traditional classroom teaching and the construction of modern classroom teaching model.
\end{abstract}

\section{The Background of the Problem}

In 2007, the flipped classroom method was proposed by teachers of chemistry Jonathan Bergmann and Aaron Sams for the purpose of enabling students who had missed the classes to catch up with the group by recording the videos for some lecutres on a subject. Flipped classroom makes teaching process change from "teaching before learning" to "learning first, then teaching", which achieves the reverse order innovation. "Reverse order innovation" brings about a new way of thinking and insight for information education. From the perspective of teaching system, flipped classroom can innovate four key elements and relations between teachers, students, teaching media and teaching contents. Especially, in 2012 Berman and Sams set up a nonprofit organization named Flipped Learning Network (FLN) to help teachers improve the knowledge and skills of inverting the classroom, which causes a rapid increase in the number of people concerned with flipped classroom. Flipped classroom has been widely welcomed since it was introduced into China in 2011. Acutally, the phenomenon of strong repercussions were aroused by foreign teaching models are not uncommon in China. Since twentieth century, several experiments have been carried out in the reform of teaching, and some foreign teaching methods have been introduced, such as the design teaching method, Dalton system, Montessori teaching method, Wen Na Tun card system, and grey system, etc. The reason why the flipped classroom becomes popular in China is not only closely related to its own excellent teaching ideas and the needs of the ages, but also has an inevitable connection with the state of education in China. It has been found that the impact of information technology on all aspects of the society, the new domestic curriculum reform and the graft preference in domestic education reform constitute the reasons for the rise of flipped classroom in China.

\section{The Concept and Characteristics of the Flipped Classroom}

\section{The Concept of the Flipped Classroom}

The flipped classroom means to readjust the organizational structure and teaching times from inside and outside classroom, and transfer learning initiative from the teachers to the students. The time of inside classroom teaching is limited, it should not be occupied for classtime teaching knowledge, but be given to students for studying independently or watching teaching video resources, such as micro lecutres, Mooc lessons, and so on. Students should take the initiative to learn, discuss and study together with teachers to solve difficult problems in the course. Teachers mainly organize learning activities and make exquisite teaching video resources. Teaching and answering questions are carried out at the same time. 


\section{The Characteristics of the Flipped Classroom}

Flipped classroom is often known as a student's practice of using network information technology, watching video before class, completing assignments and discussions in class. Indeed, flipped classroom can not be separated from the support of technology, but this is merely an understanding of flipped classroom from technology or tool level. We should deeply understand the spirit of the flip classroom mode and the profound meaning of teaching theory. Its influences on teaching and studying mainly includes the following aspects:

The change of teacher's work. In the traditional teaching mode, the main works of teachers are teaching and correcting homework. However, in the flipped classroom, teachers should make beautiful teaching videos. Therefore, teachers may become the director of the lecture words, the performers of teaching videos, the planners and the modifiers of the video resources. As a result, the teacher's identity becomes the status of "screenwriter", "director", "actor", "post production", "teaching assistant" and so on. So, in nowadays teachers must master the teaching technologies and skills for producing modern teaching resources.

The change of student's learning model. Students are passively accepted knowledges in the traditional classroom. Conversely, in the flipped classroom the students' learning model becomes actively and individualized.

The change of teaching time. The traditional classroom teaching is carried out according to the teaching schedule arranged by the university, and should be obeyed strictly. On the contrary, time in flipped classroom is mainly used to discuss and study knowledges together. Once students want to learn, they can watch teaching videos and other resources freely. After classroom, they can launch discussions online at any time.

The change of teaching resources. Traditional teaching resources generally includes teaching materials and guidance books, while there are more teaching resources for flipped classroom: materials, guidance books, online open curriculum resources, micro courses, forums, mobile terminals, e-books, blogs, micro-blog and some other electronic resources.

\section{Discussion on Challenges Produced by Flipped Classroom}

The mode of flipped classroom emphasizes " learning first, then teaching " and "teaching by learning" and highlight the autonomy and difference of students in their learning activities, which has positive value for promoting the development of students. Influenced by many factors, such as the traditional education culture, the educational concept and the actual teaching conditions, the introduction of flipped classroom model to China will encounter the problem of local adaptability. Both the teachers and the students will face a series of realistic challenges in the process of carrying out flipped classroom.

\section{Challenges for educational conception}

Conception is the belief and guiding principle of human action. It has a great directional effect on human behavior. The educational ideas mainly include management conception, teacher's view and student's view. As an educational administrator, it is often difficult to change the old model of teaching. Even if there is a change in mind, the influence of pressures from parents and school employment rate will lead to the slow progress of the reform. Compared with autonomous learning, students are more accustomed to listening in class, which will lead to be lack of creative spirit and the ability of studying actively. Therefore, the conception is the biggest challenge to flipped classroom.

\section{Challenges for teachers technological pedagogical and content knowledge}

In order to carry out the "flipped classroom", teachers need to know and even master the usage of network video production tools, audio technology, visual expression, teaching content segmentation and teaching case digital processing, resources uploading and downloading, and other technical problems of searching and making resources. The effective integration of three core elements, such as the knowledge of subject teaching method, knowledge of integrated technology and the teaching method of integrated technology, can effectively provide teaching media resources for learner's self-study. 


\section{Challenges for discipline adaptability}

According to the reports both from home and abroad, most of the flipped classrooms are sucessfully practiced in science courses. Therefore, the flipped classroom seems to be more applied to science courses because most of the science courses are knowledge-based, and the knowledge points are clear. The main task of teaching is to teach concepts, formulas, principles and experimental processes clearly. These can be easily displayed in video. But liberal arts teaching often needs interaction between teachers and students, which requires communication from viewpoints and emotions. These are likely to be easier to do in traditional classrooms. Therefore, how to apply flipped classroom to liberal arts courses is a matter in practice and theory.

\section{Challenges for the network supporting environment and learning conditions}

The development of flipped classroom requires providing corresponding software and learning platform. First, video files with good audio-visual effects and medium size are recorded and placed on the learning platform. This learning platform can not simply provide online viewing and downloading services, but also requires management, social interaction, evaluation and other functions. This platform enables teachers to monitor and record students' learning conveniently, and enable students to communicate with other learners or teachers in an instant and quick manner. The platform may also need the functions of online testing and grading. Therefore, these preparements require a lot of financial and technical support.

\section{Challenges for students and their parents}

In traditional teaching, the way of communication between teachers and parents is mainly through irregular parents' meetings or letters. Parents are most concerned about the performance of students in the classroom, while teachers can only express their views in a general way, which can not give parents intuitive feelings. On the contrary, the first step of study the flipped classroom resources can be completed at home. So, teachers and parents can reach a cooperative mechanism to enable parents conduct effective guidance and supervision, and assist teachers to complete the teaching. Establishing a good learning environment for the students can promote their autonomous learning.

\section{Challenges for teaching evaluation system}

The evaluation of teaching effectiveness by traditional teaching mode is mainly based on the examination and sometimes considering the performance at ordinary time. Obviously, the traditional evaluation method can not be used to test and reflect students' performance and learning activities in the flipped classroom. In the process of studying before class, students' attitude, progress, and mastery of knowledge should be considered. These factors may be judged according to the relevant records from learning platform. In classroom, we need to design reasonable evaluation model that can cover multiple factors to evaluate students' homework completion and participation in classroom activities, etc. Moreover, this assessment may not be completedly constructed by teachers. It needs the participation of students, their peers and parents. Therefore, the flipped classroom requires a multi-angle and multi-mode evaluation system.

\section{Conclusion}

As a kind of "Reverse order innovation", the flipped classroom has changed the roles of teachers and students, the distribution of teaching and learning time and the knowledge carrier, which has brought great impact and "flipping" to the traditional classroom. It is also an innovation of the mixed learning method. The essence of flipped classroom is to return to the logical starting point of teaching activities - student learning. In the teaching activities, "teaching" is the condition and "learning" is the noumenon. The logic of the existence of the teacher's "teaching" lies in the "learning" of the students. Actually, the learning activity is the real logical starting point of all education activities. In a word, the flipped classroom is a new teaching mode produced by the development of information technology. It is very beneficial to the students' learning. In this paper, we mainly discusses some questions that need to be solved in the practice of flipped classroom from these aspects including its concept, impacts and the challenges brought by flipped classroom. 


\section{Acknowledgements}

This work is supported by the project of Changzhou University (No.2015XSJ11 and No.CDGZ2016002)

\section{References}

[1] K Chilingaryan, E Zvereva. Methodology of flipped classroom as a learning technology in foreign language teaching [J]. Procedia-social and behavioral sciences, 2017(237): 1500-1504.

[2] C Lewis, D Chen. Implementation of a flipped classroom approach to promote active learning in the third-year surgery clerkship [J]. The American journal of surgery, 2018(215): 298-303

[3] Michille. University teachers' innovative teaching behavior and the relationship between the innovative ability of college students Investigate [J]. Journal of teaching research, 2013, 15-18.

[4] C Liebert, D Lin, M Mazer. Effectiveness of the surgery core clerkship flipped classroom: a prospective cohort trial. The American journal of surgery, 2016,211(2): 451-457.

[5] H Tatum, B Schwartz. Classroom participation and student-faculty interactions: does gender matter? Journal of High Education. 2013,84(6): 745-768.

[6] J Linhart. Teaching writing in a mathematical modeling course. PRIMUS, 2014,24:594-607.

[7] Y Zheng, Y Wu. Approaches for improving professors' teaching arts in top universities [J]. Journal of UESTC (Social sciences edition), 2010(12):107-109.

[8] J Bowen. Teaching naked: How moving technology out of your college classroom will improve student learning. San Francisco, CA: Jossey-Bass, 2012.

[9] G Mason, T Shuman. Comparing the effectiveness of an inverted classroom to a traditional classroom in an upper-division engineering course. Education, 2013,56(4):430-436

[10] S Kellogg. Developing online materials to facilitate and inverted classroom approach. in Proc. ASEE/IEEE Frontiers Educ. Conf., San Antonio, TX, USA, 2009.

[11] R Wu, T Wang. Flipped classroom: practical challenges faced by teachers and corresponding strategies. Journal of research. 2017,2:112-122

[12] J Wang. The Esence of Flipped Clasroom. Journal of higher education, 2016,37(8):53-59

[13] Z Ping, D Lin. Flipped classroom: theory, development history and effectiveness. Journal of eduactional studies, 2017,13(1):46-55. 